\title{
O Phármakon das operações urbanas consorciadas: O Caso de Belo Horizonte-MG
}

\section{The Phármakon of urban consortium operations: The case of Belo Horizonte-MG}

\author{
Vera Lúcia Pena \\ Bacharel em Engenharia Ambiental e Sanitária pelo \\ Centro Federal de Educação Tecnológica de Minas Gerais, Brasil \\ veralpena12@gmail.com \\ Vandeir Robson da Silva Matias \\ Doutor em Geografia, Professor do Centro Federal de \\ Educação Tecnológica de Minas Gerais, Brasil \\ vandeir@,cefetmg.br \\ Matusalém de Brito Duarte \\ Doutor em Psicologia, Professor do Centro Federal de \\ Educação Tecnológica de Minas Gerais, Brasil \\ matusalem@,cefetmg.br
}

\begin{abstract}
Resumo
A Operação Urbana Consorciada (OUC) é um instrumento previsto no Estatuto da Cidade (Lei 10.257/2001) que tem sido utilizado nas cidades brasileiras, com intuito de promover transformações urbanísticas, melhorias sociais e valorização ambiental, levando em consideração as diretrizes definidas no Plano Diretor. Em Belo Horizonte esse instrumento de política urbana está cada vez mais presente na viabilização de intervenções de grande escala. Nesse contexto, este trabalho tem como estudo o projeto da operação urbana consorciada Antônio Carlos, Pedro I, Leste e Oeste localizado no município de Belo Horizonte, denominado anteriormente como OUC Nova BH. O objetivo principal deste estudo é avaliar os impactos socioambientais da implementação do projeto desta operação, com o auxílio da categoria Phármakon. Essa categoria irá analisar em quais proporções as Operações Urbanas Consorciadas (OUC) poderiam ser consideradas "remédio" ou "veneno" para as questões ambientais e sociais. Para o desenvolvimento deste trabalho, foi realizada uma revisão bibliográfica, dados do projeto da OUC e softwares de linguagens computacionais que auxiliaram na análise. Por fim, conclui-se que esse instrumento de transformação do espaço urbano precisa de melhorias e tem grandes desafios para que seus objetivos sejam alcançados. Inseridos nesse contexto, os estudos e discussões acerca do tema são de grande importância para garantir que sejam realizadas melhorias nos planos de operações consorciadas já existentes.
\end{abstract}

Palavras chaves: Estatuto da Cidade. Operação Urbana Consorciada. Impactos Socioambientais.

\begin{abstract}
The Syndicated Urban Operation (OUC) is an instrument predicted in the Statute of the City (Law 10.257/2001) that has been used in the Brazilian cities, intending to promote town planning transformations, social improvements and environmental increase in value, taking into account the directives defined in the Master plan. In Belo Horizonte, this instrument of urbane politics is more and more present in the feasibility of large-scale interventions. In this context, this work takes as a study the project of the urbane operation when Antônio Carlos, Pedro I, Leste e Oeste located in the local authority of Belo Horizonte, called previously like OUC New BH. The main objective of this
\end{abstract}


study is to value the social and environmental impacts of the implementation of the project of this operation, with the help of the category Phármakon. This category will be going to analyse in which proportions the Syndicated Urban Operation (OUC) might be considered "a medicine" or "poison" for the environmental and social questions. For the development of this work, a bibliographical revision was carried out, when they were given the project of the OUC and software of computational languages that they helped in the analysis. For end, it ends what this instrument of transformation of the urbane space needs of improvements and has great challenges so that his objectives are reached.

Keywords: Statute of the City, Syndicated Urban Operation, Impacts Socioambientais.

\section{INTRODUÇÃO}

As Operações Urbanas Consorciadas (OUC) são instrumentos de política urbana instituídos pelo Estatuto da Cidade (Lei Federal n 10.257/2001). A OUC caracteriza-se por um conjunto de intervenções urbanísticas e estruturais coordenadas pelo poder público municipal, com a participação dos moradores, proprietários, usuários permanentes e investidores privados (AGUIAR, 2011). Nas médias e grandes cidades brasileiras esse instrumento está cada vez mais presente no planejamento e gestão do uso do solo urbano, por facilitar a ação do governo em relação às obras que visam alcançar transformações urbanísticas estruturais, melhorias sociais e valorização ambiental (FASTOFSKI et al., 2017).

As alterações urbanísticas previstas nas OUCs seriam a implantação de serviços públicos, pavimentação de vias, sistemas de saneamento, transportes públicos, entre outras. No que refere as melhorias sociais, elas consistem na implantação de equipamentos comunitários como, postos médicos e escolas, construção de centros habitacionais para a população de baixa renda, e estímulo à oferta de bens e serviços de consumo. A valorização ambiental nesses projetos compreende-se pela preservação do meio ambiente e dos recursos naturais, implantação de praças e parques, bem como a valorização do patrimônio histórico (BRASIL, 2001).

Apesar das ações de melhoria e dos benefícios produzidos, as Operações Urbanas Consorciadas também trazem impactos negativos tanto para as questões sociais quanto para as questões ambientais, tais como gentrificação, especulação imobiliária, poluição, aumento da demanda por infraestrutura. Nesse sentido, é de suma relevância avaliar os impactos socioambientais da implementação deste instrumento, visando garantir sua melhoria para o contexto urbano atual.

A categoria Phármakon supõe que existe uma transição entre a cura e a intoxicação, de forma a determinar em que medida uma situação pode ser entendida como tal. Phámarkon significa Farmácia em grego arcaico o que significa remédio ou veneno dependendo da sua dosagem (MATIAS, 2011). O presente artigo pretende discutir as Operações Urbanas Consorciadas a partir deste conceito, analisando em quais proporções as OUCs poderiam ser consideradas "remédio" ou "veneno" para as questões ambientais e sociais. 
Inseridos nesse contexto, os estudos e discussões acerca do tema são de grande importância para garantir que sejam realizadas melhorias nos planos de operações consorciadas já existentes. Dessa forma, o objeto utilizado como estudo do artigo é a OUC Antônio Carlos e Pedro I, Leste e Oeste, situada em Belo Horizonte/MG. Pretende se de forma geral avaliar os impactos socioambientais a partir do projeto de implementação da Operação Urbana Consorciada Antônio Carlos, Pedro I, Leste e Oeste do município de Belo Horizonte. Especificamente o que se quer é avaliar os relatórios técnicos: Estudos de Impacto de Vizinhança e registros da participação popular na discussão do projeto e levantar os impactos sociais e ambientais existentes em uma Operação Urbana Consorciada a partir da categoria de análise Phármakon.

Sendo assim, o presente artigo tem como objetivo realizar um estudo de caso da Operação Urbana Consorciada Antônio Carlos e Pedro I, Leste e Oeste, localizada no Município de Belo Horizonte. Essa operação apresenta uma grande extensão, devido principalmente, a área em que será inserida e a quantidade de pessoas afetadas direta e indiretamente. No município de Belo Horizonte existe a Operação do Barreiro, entretanto, a que escolhemos se destaca pela quantidade de dados e registros que podem ser acessados, sendo possível fazer uma avaliação mais consistente.

Os procedimentos metodológicos foram divididos em três etapas: primeiramente foi feita uma revisão bibliográfica pertinente ao tema, que auxiliou na análise dos documentos. A segunda parte consistiu em levantar dados secundários referentes ao projeto, disponibilizados no site da Prefeitura de Belo Horizonte, tais como: Proposta da OUC, Relatórios técnicos, Estudo de impacto de vizinhança (EIV) e registros participativos, os quais foram tratados e analisados. Para auxiliar nessa análise, foram utilizados softwares de linguagens computacionais que produziram nuvens de palavras com suas respectivas ligações. Na terceira parte apresentamos uma avaliação crítica a partir do Estatuto da Cidade e do Plano Diretor, e os impactos socioambientais de acordo com a categoria de análise Phármakon.

\section{ESTUDO DE IMPACTO DE VIZINHANÇA COMO INSTRUMENTO DA GESTÃO URBANA}

O Estatuto da Cidade, o qual defende que o meio ambiente urbano deve ser justo, equilibrado e sustentável, determina que toda atividade econômica deve ter o planejamento adequado por parte do administrador público, considerando os limites de sustentabilidade ambiental (BRASIL, 2001). Segundo Santin e Marangon (2009), esse instrumento evidencia a importância da gestão democrática municipal a partir do direito de cada cidadão na participação das ações urbanísticas para o desenvolvimento equilibrado das cidades, garantindo que sejam sustentáveis para as presentes e futuras gerações. Essa participação é fundamental na busca do equilíbrio entre interesses do poder público, grandes organizações, e das necessidades da população (MAGANHINI; MARTINS, 2014). 
O Estatuto da Cidade traz instrumentos tributários, financeiros, políticos e jurídicos para auxiliar o município no controle e planejamento do seu território. Existem os que são obrigatórios e indispensáveis, como exemplo, a definição do perímetro urbano, planejamento, o cadastro e a cobrança do Imposto Predial e Territorial Urbano (IPTU) (BRASIL, 2004). Os instrumentos que se aproximam do trabalho em questão são: Outorga Onerosa do Direito de Construir, Estudo de Impacto de Vizinhança (EIV), Operações Urbanas Consorciadas e o Plano Diretor.

Um instrumento de natureza socioambiental analisado nesse trabalho está no artigo 36 do Estatuto da cidade. Trata-se do Estudo de Impacto de Vizinhança que deve ser regulamentado por lei municipal, em que serão estabelecidas quais atividades públicas e privadas nas áreas urbanas e empreendimentos que deverão ser submetidos por este estudo. Além disso, a obtenção de licenças de instalação, ampliação ou funcionamento só serão concedidas após aprovação do EIV (BRASIL, 2001).

O Estudo de Impacto de Vizinhança é um instrumento de política urbana que avalia os efeitos positivos e negativos de empreendimentos ou atividades presentes no ambiente urbano em relação à população residente na área e nas proximidades. Esse estudo permite avaliar alternativas locacionais e tecnológicas para inserção do empreendimento, bem como a tomada de medidas preventivas para evitar o desequilíbrio do crescimento urbano e garantir condições adequadas para a população potencialmente afetada (ALVES e PASQUALETTO, 2013). O referido estudo deve indicar as mudanças urbanísticas produzidas pelo empreendimento, e explicitar como se dará a valorização ou a desvalorização imobiliária no entorno do empreendimento. Nesse sentido, é essencial reconhecer a população beneficiada ou prejudicada com a valorização ou desvalorização imobiliária, e os impactos sociais que poderão ser gerados. Assim, é estabelecido os segmentos sociais que poderão ser atraídos ou expulsos da área em função da implantação do empreendimento, além da possibilidade de alteração no perfil social e características culturais da vizinhança, desencadeando no processo de gentrificação (CARVALHO FILHO, 2006).

O EIV complementa instrumentos como Zoneamento, Código de Obras e Postura, os quais estabelecem normas de ordenamento espacial urbano. Esse Estudo de Impacto de Vizinhança prevê a participação popular, dando espaço para que a população afetada pelo empreendimento exponha sua opinião. Isso não acontece com o Zoneamento, uma vez que atividades que não são de interesse da população são permitidas (BATISTA; DIAS, 2008).

Segundo BRAGA (2001), existem Estudos de Impacto de Vizinhança elaborados nos municípios que não contemplam as análises relativas aos impactos socioeconômicos, sendo adotados procedimentos que destoam da realidade local. Nesse contexto, um estudo de impacto coerente deve conter os aspectos socioeconômicos para promover um desenvolvimento econômico que garanta os direitos fundamentais a população. Ademais, um Estudo de Impacto de Vizinhança deve contemplar 
o diagnóstico da área e analisar todos os impactos provenientes das atividades e empreendimento implementados. Isso permite que medidas corretivas e compensatórias sejam adotadas, além do monitoramento dos impactos (CARVALHO FILHO, 2006).

Durante o desenvolvimento do EIV é necessário que a população e o corpo técnico participem na avaliação de impactos e na escolha das medidas mitigatórias e compensatórias. Isso permite que a gestão urbana seja democrática e responsável, promovendo mudanças pautadas em um meio ambiente sustentável e equilibrado (DUARTE, 2007).

A função do planejamento urbanístico é de competência do poder público municipal, o qual deve gerir e planejar a cidade a partir de uma política urbana que tem como objetivo atender a função social e garantir o bem-estar dos seus habitantes. Nesse sentido, será estabelecido um Plano Diretor para cada cidade, em que o planejamento urbano deverá ser aprovado pela Câmara Municipal (ALMEIDA et al., 2017).

Uma das alterações decorrentes do novo Plano Diretor, referente à Operação Urbana Consorciada Antônio Carlos/Pedro I, Leste/Oeste trata-se das áreas de amortecimento, que são pontos de transição até locais fora da OUC, que exigem adensamento mais moderado (ALMEIDA et al., 2017). Ao comparar a Lei Municipal 7.165/96 com a Lei Municipal 11.181/19, é possível perceber algumas mudanças como: retirada do artigo 69-A do antigo Plano Diretor que tratava dos locais previstos para ocorrer as operações urbanas; e no que refere ao conteúdo da lei especifica da OUC, foram acrescentados sete tópicos, tornando-o mais completo e detalhado (MINAS GERAIS, 2019). Até novembro de 2019, estão sendo discutidas emendas relacionadas ao novo Plano Diretor (lei Municipal 11.181/19), bem como a possibilidade de junção dos conteúdos do novo PD e da legislação de parcelamento, ocupação e uso do solo, transformando em uma única lei (PBH, 2019).

\section{AS OPERAÇÕES URBANAS CONSORCIADAS: PRÁTICAS CONTEMPORÂNEAS DE GESTÁO URBANA}

O Estatuto da Cidade, desenvolvido com o intuito de estabelecer diretrizes gerais de política urbana, propõe instrumentos para colocar em práticas as diretrizes contempladas nos artigos $182 \mathrm{e}$ 183 da Constituição Federal de 1988 (BRASIL, 2001). A Operação Urbana Consorciada é um instrumento instituído pelo Estatuto da Cidade, com a parceria entre o poder público municipal e a iniciativa privada para realizar intervenções pontuais, alcançando o pleno desenvolvimento e a eficaz ocupação do solo urbano (FASTOFSKI et al., 2017).

Segundo Dallari e Ferraz (2006), as transformações urbanísticas estruturais desse instrumento promovem: modificação dos índices e características de parcelamento, uso e ocupação do solo e subsolo; alterações das normas edilícias, considerando o impacto ambiental delas decorrente; e regularização de construções, reformas ou ampliações executadas em desacordo com a 
legislação vigente. Além das transformações urbanísticas estruturais, as melhorias sociais e a valorização ambiental também fazem parte dos objetivos das Operações Urbanas Consorciadas. As melhorias sociais compreendem implantação de escolas, postos de saúde, espaços comunitários para lazer, eventos, esportes, reuniões e construção de centros habitacionais. No que tange a valorização ambiental, constitui-se por toda a preservação do meio ambiente, englobando o meio ambiente artificial, cultural, e principalmente, o ambiente natural (MAGANHINI; MARTINS, 2014).

É importante destacar que as intervenções realizadas pelas operações devem atender as próprias necessidades do projeto, podendo ser necessárias à implantação de unidades de habitação de interesse social, melhorias e reurbanização. Essas ações têm como objetivo assegurar as condições adequadas para as famílias que sofreram consequências pelas obras previstas na lei específica (AGUIAR, 2011). Entre as exigências do Estatuto da Cidade, está a necessidade de um conteúdo mínimo para o plano de OUC (que constará em Lei municipal específica, baseada no Plano Diretor) para atingir um resultado urbanístico, estabelecendo, pelo menos (BRASIL, 2008):

1) Definição da área a ser atingida;

2) Programa básico de ocupação da área;

3) Programa de atendimento econômico e social para a população diretamente afetada pela operação;

4) Finalidades da operação;

5) Estudo prévio de impacto de vizinhança;

6) Contrapartida, a ser exigida dos proprietários, usuários permanentes e investidores privados, em função da utilização dos benefícios previstos nos incisos I e II do $\S 2^{\circ}$ do artigo 32 do Estatuto da Cidade;

7) Forma de controle de operação, obrigatoriamente compartilhado com representação da sociedade civil.

As Operações Urbanas Consorciadas têm gerado no Brasil o processo de gentrificação. O termo gentrificação foi definido pela socióloga Ruth Glass em 1964, tendo maior foco na questão do mercado imobiliário e na substituição da população com menor poder aquisitivo pela nova classe média (RANGEL, 2015). O referido termo não está somente relacionado às mudanças na qualidade, composição, distribuição da força de trabalho, mas também na reorganização do espaço para produção, circulação e consumo de mercadorias. A gentrificação engloba um complexo processo de reestruturação urbana ligada à reorganização espacial (FURTADO, 2014).

Nesse contexto, as Operações Urbanas Consorciadas têm como consequência a gentrificação, ou seja, as áreas valorizadas por essa operação passam por um processo de substituição da população para uma de maior poder aquisitivo. Esse movimento acontece devido ao aumento dos preços de serviço, preços dos alimentos, taxas públicas, resultando na não condição da população de baixa renda de permanência naquela área. Nessa área valorizada, há substituição pela população colocada na categoria de classe média (MEDEIROS, 2018). 
De acordo com Jayme e Neves (2010), o processo de transformação do espaço público tem dois aspectos importantes: os seus usos e a interações segregacionistas. Isso ocorre, pois a substituição da população torna a separação de classes mais evidente, refletindo visualmente no espaço urbano em que as classes baixas ocupam áreas mais distantes, onde há a concentração de aglomerados. Sendo assim, a construção desse trabalho irá ajudar para que sejam feitas melhorias nos planos urbanísticos realizados para as Operações Urbanas, minimizando os impactos como gentrificação, segregação que estão presentes nas OUCs.

\section{RESULTADOS E DISCUSSÕES}

Nesse tópico, apresentaremos os resultados das análises que subsidiarão as discussões acerca dos impactos das Operações Urbanas, considerando a categoria de análise Phármakon (remédio e veneno) a partir das informações levantadas e da revisão bibliográfica.

\subsection{Análise do Diagnóstico da Área}

A Operação Urbana Consorciada Antônio Carlos e Pedro I, Leste e Oeste estudada envolve uma área de $30,4 \mathrm{~km}^{2}$, densidade demográfica média de 7685,70 hab/km², 99 bairros que são compostos por 909.306 moradores, o que corresponde a 36\% da população de Belo Horizonte. A OUC está localizada na porção central de Belo Horizonte, Minas Gerais e abrange também os trechos da Avenida dos Andradas, Tereza Cristina - Leste e Oeste - que pertencem ao Ribeirão Arrudas. A Área de estudo abrange o trecho Norte/Sul, onde está presente o Transporte Rápido por Ônibus (BRT), cujo objetivo é a melhoria do sistema de transporte público e o trecho Leste/Oeste, onde está localizado o Metrô (Figura 1).

As áreas verdes da região apresentam fisionomias diversificadas, e ao longo dos dois eixos, encontram-se vastas áreas verdes com significativa relevância ambiental. No sentido Leste/Oeste a vegetação arbórea arbustiva é predominante, tendo como espécies a Leucena, Sibipiruna e Sansão do Campo. Esse tipo de vegetação terá um grande peso na formação de um corredor verde na extensão da OUC. Em relação à bacia hidrográfica, os trechos Norte/Sul estão localizados na bacia dos Ribeirões do Isidoro e Onça, exceto nos bairros Lagoinha e Bonfim, que estão inseridos no Ribeirão Arrudas. Já o eixo Leste/Oeste está totalmente localizado na bacia do Ribeirão Arrudas (PBH, 2015). 


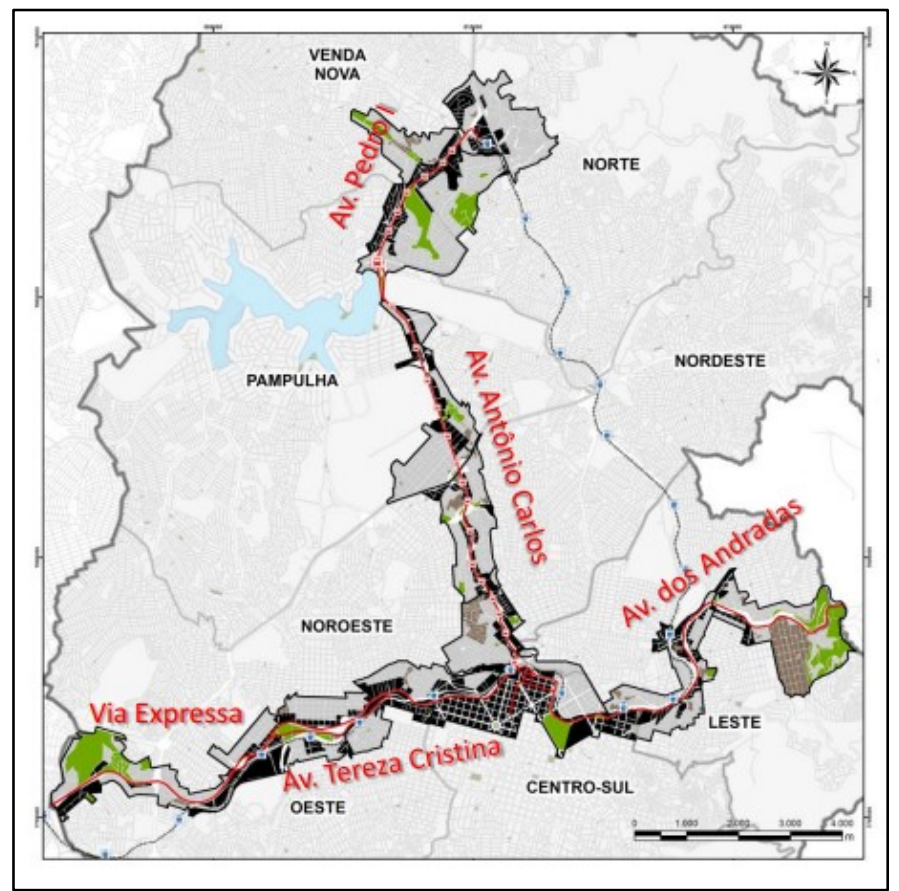

Figura 1 - Mapa da área de intervenção da OUC.

Fonte: Apresentação da OUC Antônio Carlos, Pedro I, Leste e Oeste - Prefeitura de Belo Horizonte, 2015.

Entre os anos de 1980 e 2000, as avenidas Dom Pedro I e Antônio Carlos, as quais ligavam o centro à região da Pampulha, passaram por um período de degradação das edificações e evasão das atividades não residenciais. Além dessa porção, a região Leste-Oeste também enfrentou essa fase de degradação que foram intensificados com a inserção de viadutos de transposição da linha férrea (PBH, 2015). Em termos espaciais, observa-se a expansão das atividades econômicas dos centros para os bairros e para os corredores viários que, por demandarem melhor infraestrutura, acabam resultando na extinção de moradias e ocupação por equipamentos ligados a atividade comercial, em sua maioria, e por atividades ligadas a prestação de serviços. Nessa lógica a ocupação dos eixos centrais e no seu entorno não são proporcionais, e seguem com um planejamento inadequado sem preocupar com a distribuição dos usos e com a gestão da infraestrutura das regiões. $\mathrm{Na}$ área da OUC existe uma concentração de indústrias e uma transposição de linha férrea, ou seja, um local apenas de passagem sem atrativos para a circulação e ocupação (FASTOFSKI et al., 2017).

Na Figura 2 é perceptível que a maior concentração de pessoas está localizada nos bairros do entorno e não no corredor.

Em relação à população residente, constata-se que áreas de ocupação consolidadas e próximas ao centro abrigam, predominantemente, população de renda média a alta, com variação entre os bairros, dependendo da proximidade da área central ou das condições de articulação viária e infraestrutura. Nesse sentido, ao analisar as regiões, é possível traçar um perfil para a população, sendo que nas extremidades dos eixos Noroeste, Leste e Norte reside a população de baixa e média renda. Já na área central, predominam usuários de transporte público, e na área centro-sul a população 
é composta pelos cidadãos com renda alta $(\mathrm{PBH}, 2015)$. No Estatuto da Cidade é regulamentado em seu artigo 33 que as Operações Urbanas Consorciadas necessitam de Estudo de Impacto de Vizinhança. Este estudo deve contemplar os impactos gerados e as respectivas medidas de prevenção, mitigação ou compensação com o intuito de se evitar o desequilíbrio do crescimento urbano e garantir condições mínimas de ocupação dos espaços habitáveis (BRASIL, 2001).

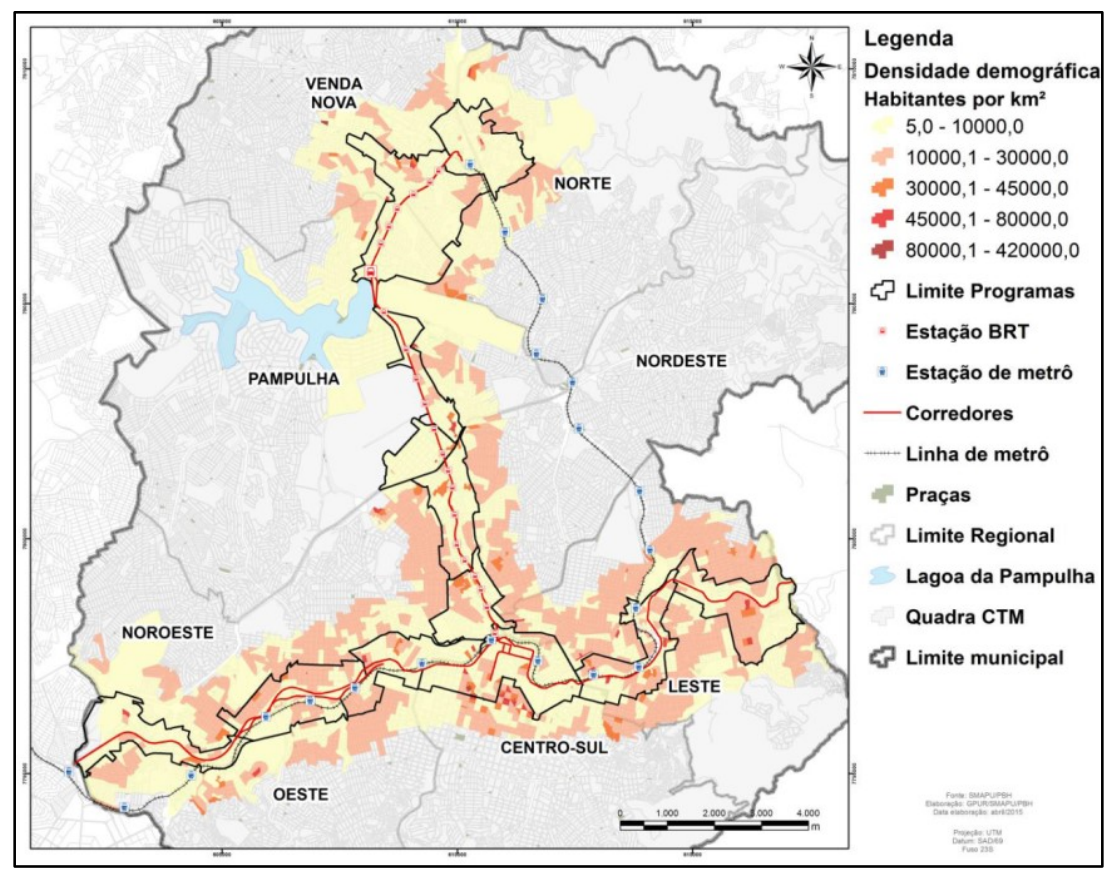

Figura 2 - Mapa da densidade demográfica da área Fonte: Apresentação da OUC Antônio Carlos, Pedro I, Leste e Oeste - Prefeitura de Belo Horizonte, 2015.

Nesse contexto, é essencial que todas as alterações do projeto, sejam previstas no estudo, a fim de se revisar as medidas e soluções propostas para a promoção da sustentabilidade. Além disso, o EIV é considerado um importante instrumento de política urbana que faz a mediação entre os interesses privados, referente aos empreendedores e o direito a qualidade urbana para os moradores e usuários do entorno. Ou seja, é um mecanismo que obriga os empreendedores a refletirem sobre as questões sociais e ambientais que seu empreendimento estará relacionado para garantir a função social da área. De acordo com o artigo 37 do Estatuto Cidade, o EIV deverá avaliar no mínimo os seguintes pontos (BRASIL, 2001):

\footnotetext{
1. Adensamento populacional;

2. Equipamentos urbanos e comunitários;

3. Uso e ocupação do solo;

4. Valorização imobiliária;

5. Geração de tráfego e demanda por transporte público;

6. Ventilação e iluminação;

7. Paisagem urbana e patrimônio natural e cultural.
} 
Segundo Prestes (2003), a legislação municipal poderia exigir que fossem analisados outros estudos além dos definidos no artigo 37 do Estatuto da Cidade, tais como: impactos de volumetria de edificações, levantamento de vegetação, impactos socioeconômicos, impactos no patrimônio histórico-cultural, e impacto nos recursos hídricos. Vale ressaltar que isso não quer dizer que deve ser obrigatório para todos os empreendimentos, uma vez que o estudo será necessário dependendo das características e das atividades do empreendimento.

Seguindo nessa linha de raciocínio, seria interessante que para empreendimentos de grande porte, considerando a magnitude do impacto causado por ele, como por exemplo, as Operações Urbanas Consorciadas deveriam desenvolver o Estudo de Impacto Ambiental, que é um documento mais completo que o EIV, visto que é um instrumento que abrange diversos tipos de intervenções. Essas intervenções propostas no projeto em conjunto apresentam impactos sociais e ambientais que estão relacionados entre si.

A tabela 1 mostra a comparação do conteúdo mínimo do EIV definido no Estatuto da Cidade em relação ao EIV da Operação Antônio Carlos e Pedro I, Leste e Oeste. De acordo com a tabela 1, é possível perceber que o Estudo de Impacto de Vizinhança da operação analisada apresenta todo o conteúdo mínimo previsto no Estatuto da Cidade. Entretanto, a valorização imobiliária é o único tema que não é tratado como um tópico no estudo, sendo apresentado dentro de subtópicos, não dando ênfase nesse conteúdo. E por ser um tema relevante, principalmente por estar relacionado a um dos impactos mais importantes (gentrificação) em uma operação, a valorização imobiliária deveria ser relatada em destaque.

Tabela 1 - Conteúdo mínimo do EIV da Operação Antônio Carlos e Pedro I, Leste e Oeste.

\begin{tabular}{|c|c|}
\hline $\begin{array}{l}\text { Conteúdo Mínimo do EIV (art. } 37 \text { do } \\
\text { Estatuto da Cidade) }\end{array}$ & $\begin{array}{c}\text { EIV da Operação Antônio Carlos e } \\
\text { Pedro I, Leste e Oeste }\end{array}$ \\
\hline Densamento Populacional & SIM \\
\hline Equipamentos Urbanos e Comunitários & SIM \\
\hline Uso e Ocupação do Solo & SIM \\
\hline Valorização Imobiliária & SIM \\
\hline $\begin{array}{c}\text { Geração de tráfego e demanda por } \\
\text { transporte público }\end{array}$ & SIM \\
\hline Ventilação e Iluminação & SIM \\
\hline $\begin{array}{l}\text { Paisagem urbana e Patrimônio Natural e } \\
\text { Cultural }\end{array}$ & SIM \\
\hline
\end{tabular}

Fonte: Próprio autor, 2019. 
No que concerne a essas recomendações, observa-se que o Estudo de Impacto de Vizinhança contém essas exigências, mas a forma como estão dispostas não são claras. Dessa maneira seria interessante que fosse utilizado recursos de tabelas e quadros para explicitar a importância do EIV para esse tipo de instrumento de transformação do espaço urbano, assim como a regra da incidência que definem quais empreendimentos devem ter o referido estudo. Além disso, ressalta-se que os itens 3), 4) e 5) devem ser apresentados de forma mais clara e detalhada visto que são pontos importantes que sem eles não seria possível atender aos objetivos da Operação Urbana.

Com a comparação do conteúdo mínimo do EIV em relação ao estabelecido na Lei Federal n. 10.257 de 2001, e também de acordo com o manual de Regulamentação e Implementação de Instrumentos do Estatuto da Cidade, não é possível fazer inferências aprofundadas sobre a qualidade do conteúdo apresentado. Essa avaliação mais profunda é descrita no Relatório de Impacto de Vizinhança (REIV) que foi realizado pela Gerência Executiva do Conselho Municipal de Política Urbana - GCPU, e também por alguns representantes do setor popular.

Os relatórios realizados por representantes da sociedade apresentam condicionantes para promover melhorias para o Estudo de Impacto de vizinhança. Nesses relatórios, é abordada a preservação do patrimônio cultural, que foi colocado em diversos momentos como responsabilidade de terceiros. Além disso, foi ressaltado que faltaram estudos para analisar mais profundamente os efeitos gerados pela construção de grandes prédios sem limite de altimetria que estão previstos na proposta da OUC. Assim como, o aumento de áreas impermeáveis, causando enchentes e deslizamentos de terra em locais mais vulneráveis. E por fim, os representantes do setor popular trataram a respeito da questão social, principalmente na garantia de moradias para população de baixa renda, assim como a realocação adequada das famílias, a fim de se evitar o processo de gentrificação. Logo, deram destaques para os temas que foram abordados no EIV, mas que ainda deixaram questionamentos.

\subsection{As Concepções do Projeto}

A proposta da OUC pode ser dividida em eixos principais que seriam: estrutural, socioambiental e econômico. As ações no eixo estrutural baseiam-se no direcionamento do crescimento das cidades próximas aos corredores do transporte público coletivo, como, metrô e BRT; e ocupação de áreas com maior infraestrutura de transporte, proporcionando um adensamento populacional para que, principalmente, os usuários de transporte público possam morar e trabalhar perto das estações do move e do metrô. Além disso, propõem-se definir as áreas verdes, as Zonas Especiais de Interesse Social (ZEIS), as quadras centrais, praças e galerias para garantir maior qualidade de vida à população que frequenta a área da operação, maior circulação de pessoas nos 
espaços livres de uso público e movimentação comercial, no caso das galerias comerciais que serão inseridas nessas regiões (ALMEIDA et. al., 2017) .

No setor econômico, pretende-se reciclar as áreas subutilizadas e desocupadas, para que sejam utilizadas como espaços públicos na proteção da identidade cultural e da população residente. Além disso, as áreas com capacidade para o transporte coletivo e infraestruturas terão incentivos para o desenvolvimento de empresas, a partir da inserção de serviços de saúde, tecnologia e turismo, favorecendo a geração de emprego e renda (PBH, 2015). As atividades do eixo socioeconômico preveem melhoria das vias que serão mais afastadas e associadas com passeios e imóveis, ou seja, melhor relação da habitação com os espaços públicos e os pedestres; investimento na infraestrutura urbana das vilas e aglomerados localizados na área da OUC; definição de incentivos para a produção pública de Habitação de Interesse Social (HIS); construções de edificações voltadas para usuários de transporte público coletivo, com condomínio de baixo custo, uma vaga de garagem e apenas um banheiro no apartamento. Além disso, também são previstas melhorias como a preservação e recuperação de imóveis com importância histórica, ampliação e melhoria das áreas verdes existentes e criação de novas, como corredores verdes, praças, parque, sendo de fácil acesso a todos os usuários da área da OUC (FASTOFSKI, et al., 2017)

Para alcançar todos os objetivos e ações propostas na área da OUC, objeto desse estudo, foram planejados doze programas, em que cada etapa é apresentada um conjunto de obras estruturantes com o intuito de promover unidades de vizinhança qualificadas, como apresentado na Figura 3.

Em relação às intervenções de amortecimento, foram definidas áreas que se dividem em: áreas de Ocupação Moderada (OM), de Ocupação Preferencial (OP) e de Proteção Ambiental (PA). Essas áreas visam uma transição das áreas do entorno com os bairros, tornando menos intenso as regiões adjacentes às áreas de amortecimento (FASTOFSKI, et al., 2017). As regiões de amortecimento da Operação Urbana dão destaque para ocupação local, considerando suas restrições e características do solo, topografia, infraestrutura existente para promoverem o equilíbrio das regiões de adensamento. Além disso, foi levada em consideração a capacidade suporte das áreas para que as questões ambientais sejam preservadas, assim como o patrimônio histórico e cultural em prol da qualidade de vida da coletividade. 


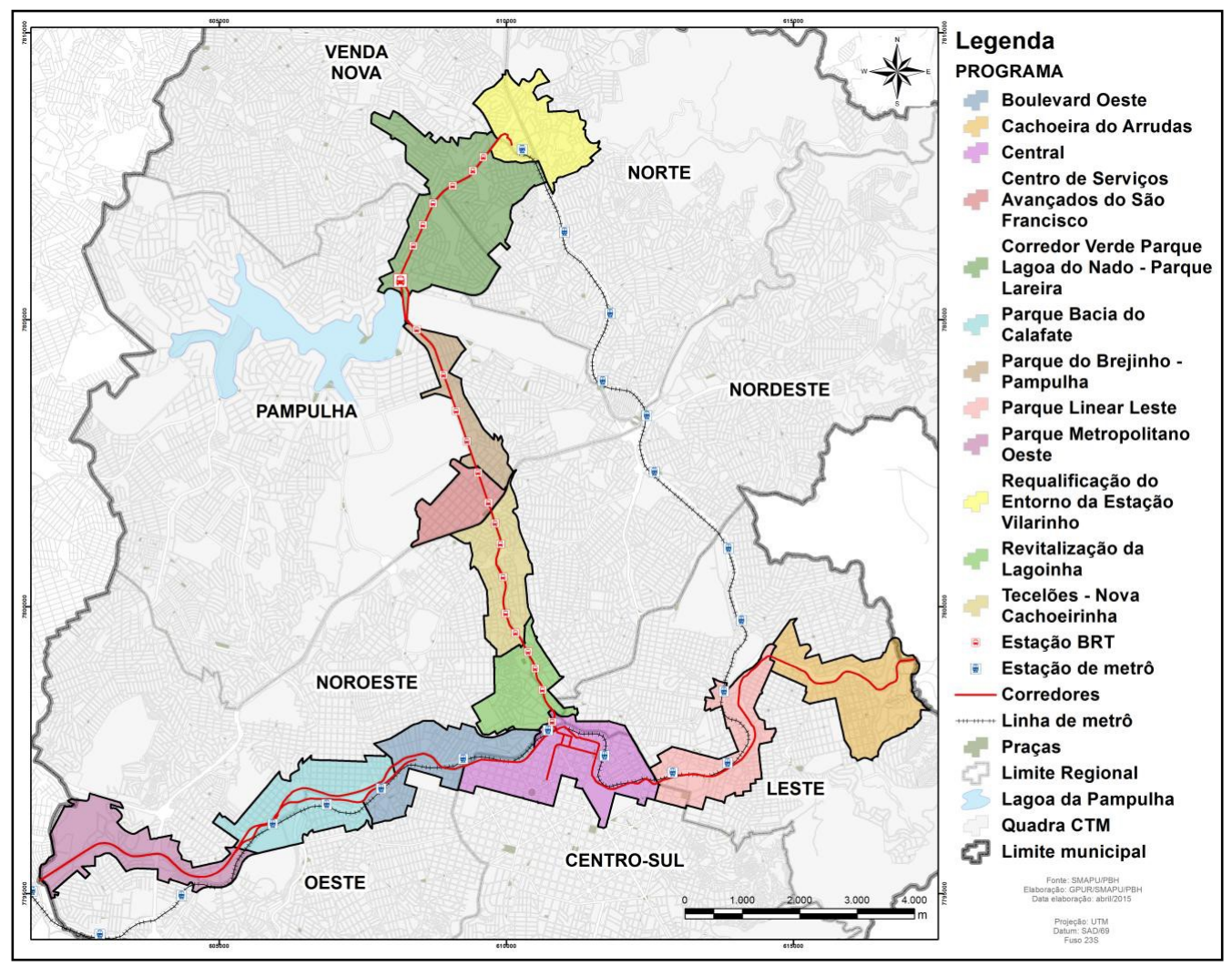

Figura 3 - Mapa dos programas da proposta da OUC

Fonte: Apresentação da OUC Antônio Carlos, Pedro I, Leste e Oeste - PBH, 2015.

\subsection{O Phármakon do projeto}

A seguir abordaremos os impactos presentes nas Operações Urbanas Consorciadas, em destaque para a OUC Antônio Carlos e Pedro I, Leste e Oeste, que serão analisadas de acordo com a categoria Phármakon, Essa categoria de análise, que se divide entre "cura" e "intoxicação", será utilizada para relatar em quais proporções as OUCs podem ser consideradas "remédio" ou "veneno".

\subsubsection{O Remédio}

As OUC em geral apresentam propostas que irão promover uma reestruturação e requalificação da área urbana, além de um novo modelo de adensamento construtivo e populacional das áreas envolvidas, garantindo a atração de comércios e serviços que levam ao desenvolvimento local, como geração de emprego. Outras propostas apresentadas pela OUC são a melhoria das condições de mobilidade urbana, principalmente devido às transformações estruturais realizadas nas grandes vias públicas e a valorização de transporte não motorizado.

Essas mudanças estão em conformação com o uso intensivo por moradias, com destaque para a população de baixa renda. Além da melhoria de áreas públicas, parques e praças; preservação e recuperação do patrimônio histórico e cultural e reforma de equipamentos urbanos e comunitários. 
Contudo, essas transformações irão promover uma maior qualidade de vida para toda a população e a preservação da história e da identidade cultural da cidade.

Desse modo, constata-se que toda a reestruturação envolvida em uma operação traz melhorias que se dividem em quatro vertentes: infraestrutura, economia, social e ambiental. Todas essas áreas estão interligadas, as quais contribuem para garantir a função social da terra. Nesse sentido, o Projeto da Operação Urbana Consorciada Antônio Carlos e Pedro I, Leste e Oeste como retratados anteriormente, preveem transformações estruturais, socioambientais e econômicas.

De acordo com as propostas e ações relatadas, constata-se que as melhorias provenientes dessa operação são: melhoria do trânsito devido a menor necessidade de deslocamento dos cidadãos; melhores condições de mobilidade urbana; maior qualidade de vida para a população; aumento das oportunidades de emprego, que está diretamente ligado ao desenvolvimento da economia da cidade, maior acesso aos equipamentos de saúde, educação, cultura e lazer; e aproveitamento de lotes vagos e subutilizados na área da OUC. Logo, o "remédio" da OUC concentra nas questões relacionadas à infraestrutura, e economia, e na mobilidade urbana, principalmente no que se refere a modificação dos índices e parâmetros de parcelamento, ocupação, uso do solo. Entretanto, de acordo com a proporção e do propósito que essas ações estão envolvidas, essas intervenções podem ser transformadas em "veneno".

Nesse sentido, faz-se necessário o acompanhamento pelos cidadãos das atividades propostas, que deverão ter seu espaço para debatê-las e suas respectivas consequências, visto que essas modificações podem facilmente transitar de um fator "bom" para "ruim", prejudicando a população afetada. Um possível fator frágil às mudanças seria o adensamento construtivo próximo aos corredores que, dependendo do local, do volume que ocorre e das suas características, poderiam acarretar em uma piora das questões climáticas e aumento do processo de ilha de calor. Outras fragilidades que podem ser observadas são a elevação do nível de ruído durante a implantação da operação, reduzindo assim a qualidade de vida de quem reside e/ou trabalha naquela ou próxima àquela porção da cidade.

Outro exemplo de impacto que pode transitar entre o positivo e o negativo seria o agrupamento de lotes extensos, autorizados devido aos parâmetros mais permissíveis de uso e ocupação do solo. Esses terrenos tem um maior potencial de reestruturação em relação ao planejamento da escala do lote. Entretanto, pode se tornar um aspecto ruim por dar espaço pra grandes empreendimentos fechados que não tem relação com a rua, dificultando a circulação de pedestres.

No que tange o incentivo ao uso do transporte coletivo e cicloviário, que ocorrerá por meio da ampliação e construção da rede de transporte com novos eixos e estações e implantação de ciclovias, tem-se a redução da utilização do transporte individual por automóvel. Contudo, a expansão da utilização da bicicleta como meio de transporte é um impacto que gera melhorias nas condições 
de acesso e de circulação, e isso reduz a saturação viária. Entretanto, quando se trata dos deficientes físicos, essa questão transforma-se em um aspecto negativo, porque não é um meio de transporte que tem a acessibilidade para esse tipo de deficiência. Nesse contexto, são necessários que sejam promovidas ações e medidas de inclusão e de acessibilidade para a população portadora de deficiência, considerando que esse tema não foi abordado explicitamente no Estudo de Impacto de Vizinhança.

\subsubsection{O Veneno}

É de suma relevância compreender primeiramente que os impactos ambientais presentes em uma Operação Urbana Consorciada, ligados à cidade, apresentam uma multidimensionalidade e, por isso, não podem ser omitidos. Seguindo essa lógica, é importante entender que os impactos ambientais estão em constante movimento por ser uma relação de alterações sociais e ecológicas. Ao fixá-los como é feito nessa pesquisa, estão sendo analisado apenas um estágio do impacto, desconsiderando sua dinâmica. Esse conhecimento de um estágio do problema permite inferir e direcionar para possíveis ações mitigadoras. Porém, é relevante não possuir uma visão fragmentada do processo, ou seja, estudar, de forma separada, aspectos ambientais como o clima, relevo, vegetação, e aspectos sociais como condições de habitação, características da população, e meios técnicos (meio artificial), resultando em uma separação dos impactos físicos e sociais (COELHO, 2011).

Nesse sentido, essa visão separada dos impactos resulta em uma distorção da classificação em positivo e negativo, desconsiderando um contexto global. Portanto, o que é considerado positivo em um momento para uma classe social e para certo local, pode não ser para outra, ou o que é positivo em um dado momento, pode não ser em outro (COELHO, 2011). Essas ideias só confirmam que, colocar os impactos de forma isolada não é uma boa maneira para identificá-los. Isso porque de acordo com as circunstâncias em que são expostos (finalidade e classe em que está envolvida), esses impactos podem transitar entre algo "bom" e "ruim". Assim, a utilização de uma categoria é uma maneira considerável para retratar essas variações.

De acordo com o projeto da OUC Antonio Carlos, Pedro I, Leste e Oeste, é possível identificar impactos que estão relacionados tanto com as questões sociais quanto com as questões ambientais. De modo geral, os impactos são:

- $\quad$ Aumento do nível de ruído;

- $\quad$ Poluição do ar;

- Intensificação do fenômeno de ilha de calor;

- $\quad$ Assoreamento de curso d'água;

- $\quad$ Erosão e deslizamento de terra;

- $\quad$ Aumento e descentralização da demanda por infraestrutura (equipamentos públicos); 
- Saturação viária;

- Aumento do tempo de deslocamento por transportes motorizados;

- Aumento do potencial construtivo sem limite de altimetria;

- Redução da ventilação e iluminação;

- Aumento da temperatura;

- $\quad$ Alteração da permeabilidade do solo;

- $\quad$ Aumento do consumo de água, energia e geração de resíduos;

- Degradação da vegetação;

- Substituição de comércios locais;

- Reassentamento da população;

- $\quad$ Alteração da ambiência urbana;

- $\quad$ Pressão sobre áreas de interesse cultural e em Vilas e Aglomerados;

- $\quad$ Gentrificação.

Uma das principais propostas prevista no projeto da OUC é o maior adensamento populacional e construtivo próximos aos eixos prioritários de transporte coletivo. Em função desse adensamento poderá ocorrer uma racionalização da infraestrutura instalada que, consequentemente a isso, irá levar ao aumento da demanda por equipamentos públicos e por infraestrutura. Concomitante a isso, em várias vias da cidade é provável que ocorra mais rapidamente a saturação viária, devido ao aumento das frotas de ônibus. Contudo, o aumento do número do transporte coletivo irá interferir negativamente no tempo de deslocamento com transportes motorizados na área da operação.

Além disso, com a maior distribuição da população pelas regiões da cidade o uso por equipamentos comunitários também se tornará descentralizado, dificultando seu acesso, devido a concentração dos equipamentos públicos já existentes. $\mathrm{O}$ aumento de construções na área da OUC sem limite de altimetria tem como consequência a obstrução da visão e a redução de iluminação e ventilação ao redor dos edifícios. Logo, construções já existentes, que possuem um menor número de andares, ficarão prejudicadas pela falta de iluminação ocasionada pelas novas edificações. Além disso, pode ser difícil o controle da temperatura no interior dos edifícios de maior porte, sendo obrigados a utilizar equipamentos para a diminuição da temperatura refletindo no aumento do consumo de energia. Isso também está diretamente ligado a dificuldade de dissipação dos gases e partículas poluentes, contribuindo para a intensificação do fenômeno da ilha de calor.

A intensificação do uso do solo e da ocupação gera uma maior impermeabilidade do mesmo, visto que serão realizadas várias obras de construção civil como, viadutos, passarelas, conjuntos residências, quadras, e empreendimentos comerciais. Assim, é necessário que seja realizado um projeto de drenagem que evite fenômenos como, enchentes, deslizamentos de terra e alagamentos, bem como o aumento de áreas verdes. A maior concentração de pessoas em torno dos corredores pode elevar o consumo de água, de energia e da geração de resíduos, sendo que se não forem dispostos corretamente podem afetar de forma negativa a população. 
Durante a realização das obras previstas no plano da OUC, haverá a movimentação de terra, bem como escavações, retaludamento e remoção de solo quando necessário. Em função desses processos, e das características do solo e da superfície poderão ocorrer desmoronamentos, deslizamentos, erosões e a compactação do solo pelo trafego de veículos e máquinas. Sabe-se que a exposição do solo combinado com a sua saturação pela chuva acelera o processo de erosão e pode levar a deslizamentos.

Concomitante a esse processo, existe a possibilidade de acontecer o assoreamento dos cursos hídricos, fazendo com que a ocorrência de alagamentos aumente. Outro impacto proveniente dessas obras é alteração da qualidade do ar devido o aumento das partículas em suspensão emitidas nos processos de escavação e terraplanagem, e também pela emissão proveniente dos veículos. A utilização de máquinas e a circulação de automóveis aumentarão os níveis de ruído, e as realizações de obras serão responsáveis por remover a vegetação existente.

A permissividade dos parâmetros de uso e ocupação do solo e do parcelamento acima dos valores definidos no Plano Diretor é um fator recorrente na área da Operação Urbana e responsável por gerar pressão sobre áreas de interesses cultural que não estão protegidas, como vilas, aglomerados e bens tombados, afetando a identidade e as moradias da população de baixa renda. Em relação a esses parâmetros e as estratégias de diversificação dos usos nas regiões, é provável que ocorra a substituição de comércios locais já existentes por grandes empreendimentos. Desta forma, os comerciantes locais são obrigados a se deslocar para outras regiões e, muitas vezes, acabam perdendo sua fonte de renda.

Esse movimento de moradores e comerciantes é devido principalmente à valorização imobiliária das regiões reestruturadas pela OUC, sendo dominado gentrificação. Nesse contexto de valorização imobiliária, torna-se inviável que a população de baixa renda continue residindo na mesma região, e por isso acontece o deslocamento para regiões mais distantes e quase sem infraestrutura. Esse impacto só reforça que a classe de menor renda não é atendida com os investimentos urbanos, e a segregação espacial se torna ainda mais aparente. A ocupação por essa população acontece de forma desordenada e intensa em áreas distantes da região central da cidade, alterando a capacidade suporte do solo. Contudo, é perceptível que os problemas ambientais nessas regiões são mais frequentes e prejudiciais se comparado com uma região ocupada por uma classe alta, onde os investimentos de estruturação das áreas são sempre realizados. Por isso, os riscos de deslizamentos, erosão e alagamentos estão presentes nessas áreas que, por sua vez, são menos valorizadas.

Outro impacto referente à questão social é o reassentamento de famílias previstos nessa operação. Essa realocação da população por conta das obras é resistida por muitos moradores, assim como a proposta do aluguel social previsto para habitantes que tem baixa renda e para comércio de 
pequeno porte. Isso acontece porque são atribuídas nessas regiões um valor sentimental pelos moradores, que acabam não querendo deixa-las com medo de perder a história e a identidade cultural que aquele local representa.

Atrelado aos impactos relatados, é imprescindível que a participação popular seja considerada e garantida em todo o processo de elaboração e implementação da OUC. A defesa e garantia da participação dos cidadãos nesse processo é papel do poder público municipal que, por sua vez, deve assegurar que os problemas vivenciados pelos moradores da região sejam discutidos junto com eles para o encontro de soluções compatíveis com a realidade urbana.

Anteriormente, a operação objeto desse estudo foi denominada como OUC Nova BH, que ficou conhecida pelas repercussões negativas a respeito da falta de participação direta da população na elaboração e acompanhamento das propostas da implementação da OUC. Essa falta de participação popular gerou incertezas no que refere à realocação de famílias de aglomerados e vilas que poderiam levar a gentrificação. A partir das irregularidades da operação, o Ministério Publico interviu paralisando sua implementação, visto que a falta de inserção da sociedade nas discussões levaria a violação do princípio de gestão democrática.

Segundo Fastofski et al. (2017), essa irregularidade do projeto da Operação Nova BH também estaria relacionada a proposta de altos coeficientes de aproveitamento que alterariam de forma significativa a paisagem urbana. Esse fato é semelhante a outras OUCs, tais como OUC Porto Maravilhas localizada no Rio de janeiro, e a OUC Faria Lima em São Paulo. Contudo, esta operação passou por uma nova reformulação e foi apresentada em 2014 como uma nova operação urbana, denominada OUC Antônio Carlos, Pedro I, Leste e Oeste (PBH, 2019).

\section{CONSIDERAÇÕES FINAIS}

Observa se que existem instrumentos existem documentos, como Estatuto da Cidade e Plano Diretor que são responsáveis por direcionar o projeto e a implementação da Operação Urbana Consorciada. Entretanto, essas duas leis ao instituírem que a OUC seja precedida de uma lei especifica que possa promover regras de parcelamento, ocupação, uso do solo e do subsolo, geram uma permissividade que apenas contribuem para os interesses dos empreendedores.

Contudo, essas liberdades proporcionadas pela legislação urbana ressaltam que as parcerias decorrentes da Operação Urbana Consorciada vêm acontecendo pelo interesse da iniciativa privada e não pela garantia das transformações estruturais, melhorias sociais e a valorização ambiental, como é definido no Estatuto da Cidade em seu art. 32, $\S 1^{0}$. Nesse contexto, as experiências no Rio de Janeiro e São Paulo confirmam essa distorção do papel da OUC, bem como a operação objeto desse estudo. 
Remédio e veneno se misturam no que concerne o projeto da OUC Antônio Carlos, Pedro I, Leste e Oeste, é possível perceber a presença de impactos a partir das propostas apresentadas. Os impactos foram relatados no Estudo de Impacto de Vizinhança de acordo com uma visão fragmentada, desconsiderando os fatores que levam a possibilidade de transição dos impactos entre algo "bom" e "ruim". Dessa maneira, o EIV da operação urbana deixa muitos questionamentos. Isso porque essa visão fragmentada dos impactos interfere principalmente na identificação e nas escolhas das ações mitigatórias e compensatórias, as quais se tornam superficiais e questionáveis, além de poderem não ser suficientes.

Em relação a participação popular, é importante destacar que o acompanhamento dos projetos, plano, programas da OUC e sua implementação, permitem que a sociedade participe de forma efetiva, ou seja, de maneira que as suas ações possam intervir diretamente no resultado de cada etapa do projeto. Entretanto, ao analisar a participação promovida pela operação estudada, destacase a superficialidade da inserção da sociedade que foi realizada por meio de palestras, audiências e oficinas, principalmente por acontecerem em dias e horários que não são acessíveis para a população. Além disso, a publicidade dada a operação, assim como os meios de informação, não foi suficiente para garantir que a população tivesse conhecimento desse instrumento.

Dessa maneira, todos esses fatos tanto relacionados aos impactos quanto relacionados a participação popular ressaltam a falta de democratização do planejamento, a qual é destacada no Plano diretor, na Constituição de 1988 e no Estatuto da Cidade. Assim, o histórico social da composição do espaço urbano se mantém desigual e segregado, e a perspectiva de melhoria não é democrática, visto que essa mudança só irá beneficiar uma parcela da população.

Por fim, a Operação Urbana Consorciada Antônio Carlos, Pedro I, Leste e Oeste, assim como as outras operações espalhadas no Brasil têm dois grandes desafios. O primeiro é promover uma reestruturação do espaço urbano que englobe de forma igualitária todas as classes da sociedade, alterando esse cenário de segregação através da promoção de uma reforma do espaço urbano que não seja movida apenas pelos interesses privados. E o segundo consiste na identificação dos impactos apresentados no EIV, que considere as relações entre sociedade e ambiente, e não somente os resultados provocados pela intervenção no ambiente.

\section{REFERÊNCIAS}

AGUIAR, C. R. G. Operação Urbana Consorciada. Revista Direito Mackenzie, São Paulo, v. 5, n. 2, p. 93-106, 2011.

ALMEIDA, R. M.; NIZZA, J. L. B. Os (des)caminhos do poder público na gestão da cidade: o caso da implantação da Operação Urbana Consorciada Nova BH em Belo Horizonte. In: ENCONTRO NACIONAL DA ASSOCIAÇÃO NACIONAL DE PÓS-GRADUAÇÃO E PESQUISA EM 
PlaneJAMENTO URBANO E REGIONAL. 17., 2017, São Paulo. Anais... São Paulo, 2017, p. 120.

ALVES, O. R.; PASQUALETTO, A. Exigência do estudo de impacto de vizinhança -EIV para empreendimentos residenciais: Estudo de caso Tropicale condomínio. In: ENCONTRO NACIONAL DE PÓS-GRADUAÇÃO E PESQUISA EM GEOGRAFIA. 10., 2013, Goiânia. Anais... Goiânia: Canone, 2013, p. 1097-1110.

BATISTA, G. T.; DIAS, N. W. Ocupação do solo Urbano: Desafio pós Estatuto das Cidades. Capítulo do Livro: Uma agenda para a Sustentabilidade Regional: Reflexão e Ação - Parte II: Desafios. UNITAU, 2008, 22 p. Disponível em: http://agro.unitau.br:8080/dspace/bitstream.pdf. Acesso em: 27 mai. 2019.

BRAGA, R. Gestão ambiental no estatuto da cidade: alguns comentários. In: CARVALHO, P. F. BRAGA, (Org.) Perspectivas de Gestão Ambiental em Cidades Médias. Rio Claro, 2001. p. 95119.

BRASIL (MINISTÉRIO DAS CIDADES). Acesso a terra urbanizada: implementação de planos diretores e regularização fundiária plena. Florianópolis: UFSC; Brasília: Ministério das Cidades, 2008.

BRASIL (MINISTÉRIO DAS CIDADES). Plano diretor participativo: guia para elaboração pelos municípios e cidadãos. Brasília: Confea, 2004.

BRASIL. Lei $\mathbf{n}^{\mathbf{0}} \mathbf{. 1 0 . 2 5 7}$, de 10/07/2001, que estabelece diretrizes gerais da política urbana. Brasília: Câmara dos Deputados, Coordenação de Publicações, 2001.

CARVALHO FILHO, J. S. Comentários ao estatuto da cidade: Lei no ${ }^{\circ}$ 10.257, de 10/07/2001 e medida provisória n. 2220, de 04/09/2001. 5. ed. Rio de Janeiro: Lumen Juris, 2006. 600p.

COELHO, M. C. N. Impactos Ambientais em Áreas Urbanas: Teorias, Conceitos e Métodos de Pesquisa. In: GUERRA, Antonio José Teixeira; CUNHA, S. B. (Org.). Impactos Ambientais Urbanos no Brasil. Rio de Janeiro: Bertrand Brasil, 2011.

DALLARI, A. A.; FERRAZ, S. Estatuto da Cidade: comentários à Lei Federal 10.257/2010. 2. ed. São Paulo: Malheiros, 2006. 86p.

DUARTE, F. Planejamento Urbano: Do estudo de impacto de vizinhança. 20. ed. Curitiba: IBPEX, 2007. 177p.

FASTOFSKI, D. C.; FACHIN, C. F.; BIANCHI, E.; MARCON, L.; BUENO, V. C. Análise da Operação urbana consorciada em Belo Horizonte, Antônio Carlos e Pedro I + Leste/Oeste. In: CONGRESSO DE RESPONSABILIDADE SOCIOAMBIENTAL. 2., 2017, Caxias do Sul. Anais... Caxias do Sul, 2017. p. 208-222.

FURTADO, C. R. Intervenção do estado e (re)estruturação urbana. Um estudo sobre Gentrificação. Cadernos Metrópole, São Paulo, v. 16, n. 32, p. 341-363, 2014.

JAYME, J. G.; NEVES, M. A. Cidade e espaço público: política de revitalização urbana em Belo Horizonte. In: Cad. CRH, Salvador, v. 23, n. 60, p. 605-617, 2010. 
MAGANHINI, T. B.; MARTINS, P. O. As operações urbanas consorciadas como instrumento de promoção do meio ambiente urbano saudável. Revista do Direito Público, v. 9, n. 1, p.101-120, 2014.

MATIAS, V. R. S. O Phármakon da democracia eletrônica na gestão territorial urbana. 2011. 243 f. Tese (Doutorado em Geografia) - Instituto de Geociências, Universidade Federal de Minas Gerais, Belo Horizonte, 2011.

MEDEIROS, S. R. F. Q. Segregação e Gentrificação: os conjuntos habitacionais em Natal. 1. ed. Natal: EDUFRN, 2018. 384p.

MINAS GERAIS. Lei $\mathbf{n}^{\mathbf{0}} \mathbf{1 1 . 1 8 1}$ de 2019. Aprova o Plano Diretor do Município de Belo Horizonte e dá outras providências. Câmara Municipal de Belo Horizonte, 08 de agosto de 2019.

PBH. Prefeitura de Belo Horizonte. Disponível em: https://prefeitura.pbh.gov.br/politicaurbana/planejamento-urbano/plano-diretor. Acessado em: 10 out. 2019.

PBH. Prefeitura de Belo Horizonte. Operação Urbana Consorciada Antônio Carlos/Pedro I+Leste e Oeste: Plano Urbanístico e Estudo de Impacto de Vizinhança. Caderno de texto, tabelas e figuras. Belo Horizonte, 2015. 353p. Disponível em: https://prefeitura.pbh.gov.br/politicaurbana/planejamento-urbano/operacoes-urbanas/consorciadas. Acessado em: 10 jun. 2019.

PRESTES, V. B. Plano Diretor e Estudo de Impacto de Vizinhança (EIV). V Conferência das Cidades, 2003. 17p.

RANGEL, N. F. A. O esvaziamento do conceito de gentrificação como estratégia política. Cadernos NAUI, Florianópolis, v. 4, n. 7, p. 40-57, 2015.

SANTIN, J. R.; MARAGON, E. G. Instrumentos de política urbana para valorização do patrimônio histórico: outorga onerosa e transferência do direito de construir. Histórias: debates e Tendências, v. 8 , n. 2, p. 365-377, 2009. 